\title{
Método multicriterial para avaliação do risco ambiental no comércio de combustíveis na primeira légua patrimonial de Belém (Pará)
}

\author{
Multi-criteria method for environmental risk assessment \\ of fuel trade within the first urban mile of Belém (Pará)
}

Leonardo Augusto Lobato Bello', Elza Claudia Fragoso², Tácio Mauro Pereira De Campos ${ }^{3}$

\begin{abstract}
RESUMO
Este artigo apresenta um modelo simplificado de análise sobre o potencial de risco associado à existência de postos de comércio de combustíveis no contexto urbano, que considera três critérios de análise: operacional, normativo e ambiental. Esses critérios estão distribuídos entre oito variáveis de controle, internas e externas, as quais são valoradas a partir de informações quantitativas e qualitativas facilmente disponibilizadas, e que foram empregadas na determinação das notas de risco de 67 postos de combustíveis existentes na primeira légua patrimonial (PLP) da cidade de Belém, Pará, o primeiro rossio da cidade, demarcado pela coroa Portuguesa em 1616, com o fim de obtenção da Nota de Risco de Postos de Combustível e produção do Mapa de Potencial de Risco dos bairros da PLP. Os resultados demonstram que a maioria dos postos de combustíveis existentes na PLP possui risco alto e poucos impõem risco grave e médio.
\end{abstract} Palavras-chave: risco; combustível; Belém; desenvolvimento urbano.

\begin{abstract}
This paper introduces a simple model to assess potential risk of gas stations in urban areas, which takes into account three dimensions of analysis: operational, normative, and environmental. These dimensions are distributed in eight internal and external control variables, which, in turn, are valued by qualitative and quantitative interpretation of easily available local data. The proposed model was applied to evaluate 67 gas stations located within the first urban mile of Belém, Pará, Brazil, which is characterized as the first demarcation of land granted by the Portuguese crown in the foundation of Belém, in 1616, in order to obtain the risk rating for gas station and also to produce the potential risk map for first urban area districts. Results show that most of the gas stations in the first urban mile presents high risk, whereas only a few possesses important and medium risk.
\end{abstract}

Keywords: risk assessment; gas station; Belém; urban development.

\section{INTRODUÇÃO}

A contaminação do subsolo e dos aquíferos subterrâneos por hidrocarbonetos oriundos de vazamentos de tanques de combustíveis ou derrame durante a operação dos postos, principalmente em áreas próximas a pontos de captação de água para abastecimento e consumo, não é um cenário ambientalmente desejado. Nesse caso, as condicionantes associadas ao transporte e à mobilidade do contaminante no meio poroso, bem como os consequentes efeitos nocivos à saúde e à integridade do meio ambiente, têm sido amplamente estudadas e identificadas (CORSEUIL; MARINS, 1997; KONEČNÝ et al., 2003; TIBURTIUS; PERALTA-ZAMORA; LEAL, 2004; CHIARAMONTE et al., 2012).
Por outro lado, as políticas públicas de mobilidade urbana ainda estão pautadas primordialmente em modais que utilizam combustíveis fósseis, elevando a demanda por estocagem de combustíveis líquidos em grandes volumes, potencializando, assim, os riscos de contaminação do solo e dos aquíferos. Segundo dados do Departamento Nacional de Trânsito (DENATRAN, 2016), a frota brasileira de veículos alcançou, em junho de 2016, a marca de 92.281.08 veículos automotores. Em âmbito regional, os dados apontam que, no mesmo período, o Pará abrigava uma frota de 1.776.209 veículos, dos quais 661.677 estavam cadastrados em diversos municípios da região metropolitana de Belém (RMB), sendo 421.750 somente na capital, Belém. Em 2011, Belém detinha 299.037 veículos.

$\square$

'Doutor em Engenharia Civil. Coordenador do Programa de Mestrado em Desenvolvimento e Meio Ambiente Urbano, Área Planejamento Urbano e Demografia, da Universidade da Amazônia (UNAMA) - Belém (PA), Brasil.

Mestre em Desenvolvimento Urbano e Meio Ambiente pela UNAMA - Belém (PA), Brasil.

${ }^{3}$ Doutor em Mecânica dos Solos. Departamento de Engenharia Civil da Pontifícia Universidade Católica do Rio de Janeiro (PUC-Rio) - Rio de Janeiro (RJ), Brasil. Endereço para correspondência: Leonardo Augusto Lobato Bello - Travessa Nove de Janeiro, 1.497, apto. 1.304 - São Brás - $66060-575$ - Belém (PA), Brasil E-mail: leonardo.bello@unama.br

Recebido em: 19/01/16 - Aceito em: 09/01/17 - Reg. ABES: 158608 
O aumento da frota de veículos na RMB acarreta aumento na demanda por combustíveis fósseis na região e, portanto, maior necessidade de armazenamento em tanques enterrados, o que eleva o risco de contaminação da água subterrânea por vazamento desses tanques, situação que tem sido reportada na região (OLIVEIRA et al., 2002).

No presente, não estão disponíveis nos órgãos ambientais estaduais e municipais informações sistematizadas e georreferenciadas sobre as características dos postos de combustíveis na RMB, muito menos sobre estudos mais aprofundados e abrangentes que produzam e disponibilizem mapas de risco em função de fontes poluidoras do subsolo. Por outro lado, estudos sobre vulnerabilidade intrínseca de aquíferos são mais corriqueiros e sua aplicação, em conjunto com estudos relacionados ao perigo de uma dada substância, tem sido realizados e reportados recentemente na região para a obtenção de mapas de risco na RMB (LISBOA; MENDES; BELLO, 2016). A importância de desenvolver um modelo simples de avaliação, que produza indicador de risco associado ao comércio de combustíveis, reside incialmente na produção de conhecimento atualmente indisponível, mas, principalmente, na possibilidade de utilização dessa informação em conjunto com modelos já consagrados de avaliação da vulnerabilidade de aquíferos, como o método DRASTIC (ALLER et al., 1987) e o método GOD (FOSTER; HIRATA, 1993). Com base nesse cenário, este artigo teve como objetivos apresentar e aplicar um modelo de análise baseado na construção de um indicador de risco associado à existência de instalações de comércio de combustíveis no contexto urbano, e estudar as relações dessas instalações com o espaço do entorno, considerando a possibilidade de contaminação do solo e dos aquíferos em decorrência de episódios de vazamento de tanques de combustíveis por deficiências de infraestrutura, operacionais ou humanas.

\section{PRIMEIRA LÉGUA PATRIMONIAL E SEUS POSTOS DE COMBUSTÍVEIS}

O território do município de Belém é dividido em duas áreas denominadas léguas patrimoniais. A primeira légua patrimonial (PLP), lócus de aplicação do modelo proposto, é a área de terra de aproximadamente 4.110 ha que constituiu o patrimônio fundiário inicial da municipalidade - o chamado "rossio" —, doado pela Coroa Portuguesa em 1627. Obedece a um traçado de uma légua - contada a partir do marco de fundação da cidade, o Forte do Presépio (hoje Forte do Castelo) (TRINDADE JÚNIOR, 1998, p. 101). Até o ano de 2015, a PLP tem se constituído como a parcela mais ocupada, edificada e valorizada da RMB, abrangendo 23 bairros: Condor, Jurunas, Cidade Velha, Campina, Reduto, Batista Campos, São Brás, Guamá, Nazaré, Cremação, Fátima, Umarizal, Marco, Pedreira, Canudos, Montese, Telégrafo, Sacramenta, Barreiro, Miramar e parte de Val-de-Cães, Maracangalha e Universitário.
Segundo dados da Agência Nacional de Petróleo (ANP, 2014), existiam, até o ano de 2014, 118 postos revendedores de combustíveis em atividade no município de Belém, sendo 105 localizados em terra firme e 13 sobre instalações flutuantes estacionadas às margens da Baía de Guajará e dos Rios Guamá e Pará. O órgão também reporta que houve pequeno aumento no quantitativo de postos existentes, somente 10, entre os anos de 2000 e 2014, em função das severas limitações impostas pelas Leis Ordinárias de Belém/PA n 8.500/2006 (BELÉM, 2006) e nº 8.625/2008, que obrigaram as empresas que detêm essa espécie de empreendimento a respeitarem distâncias mínimas entre si e em relação às construções de usos especiais. Apesar disso, Fragoso (2014) destaca a existência de instalações em pleno funcionamento em áreas de terreno baixo e encharcado (várzea) ou em locais muito próximos a cursos de água e canais de drenagem urbana.

Por sua vez, dados da ANP (2014) apontam que existiam na PLP de Belém 67 postos revendedores em operação em 2014, distribuídos de maneira aleatória em 18 dos seus 23 bairros. A concentração desses postos por bairro não é uniforme, isto é, há bairros com elevada quantidade de postos (p. ex. 11 postos) e outros com apenas 1 (Figura 1). O total de postos na PLP reúne capacidade de armazenamento em tanques subterrâneos de cerca de 5.110.000 litros de combustíveis (ANP, 2014).

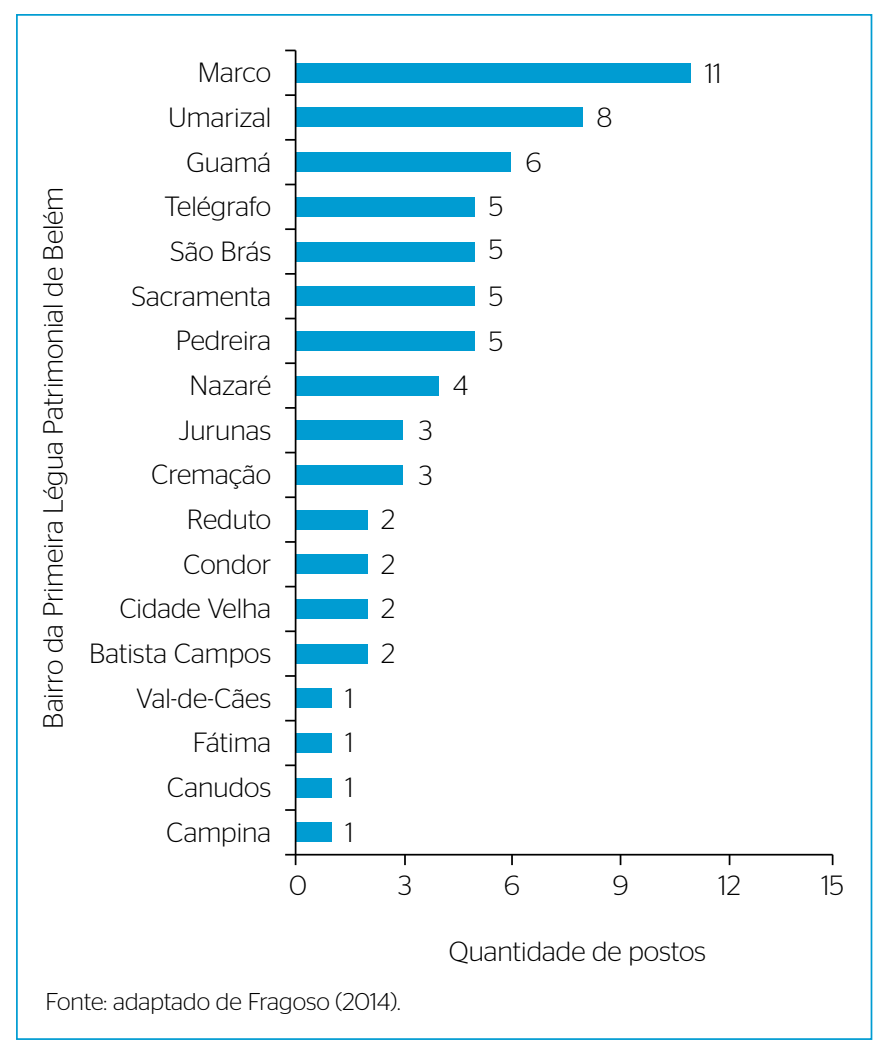

Figura 1 - Distribuição dos postos de combustíveis por bairros na Primeira Légua Patrimonial de Belém. 


\section{MATERIAIS E MÉTODOS}

\section{Nota de Risco de Postos de Combustíveis}

O modelo conceitual aqui descrito se baseia na premissa de que qualquer posto de revenda de combustível, apesar de atender aos requisitos técnicos e legislativos mínimos, apresenta certo nível de risco ao meio ambiente e à população do entorno, o que é inerente ao tipo e às características dos serviços oferecidos, constituindo as condicionantes internas, além de aspectos físicos, antrópicos e bióticos do seu entorno, que constituem as condicionantes externas do problema. Entende-se, portanto, que o risco oferecido por um posto de combustíveis ao ambiente pode ser maior ou menor quando comparado a outro posto que tenha a mesma capacidade operacional, mas também condicionantes externas agravantes ou atenuantes, como, por exemplo, a existência ou não de corpos hídricos próximos, podem fazer com que o risco de vazamento de combustível no local seja valorado em função dos critérios de análise. Nesse sentido, TERRÉS et al. (2010), com base em estudos realizados na Espanha, defendem que as distâncias mínimas dos postos de combustíveis a residências e a outras construções mais vulneráveis aos impactos, como hospitais, centros de saúde, escolas e asilos, devem ser de 50 e $100 \mathrm{~m}$, respectivamente, a fim de minimizar eventuais efeitos negativos à qualidade de vida e à saúde da população. Por sua vez, Moschini, Santos e Pires (2005), após realizar estudo em postos de combustíveis na cidade de São Carlos, São Paulo, defendem que é necessário reconhecer que tais equipamentos urbanos são fontes potenciais de contaminação e risco ambiental e que, portanto, é essencial considerá-los como elementos a serem gerenciados de maneira a garantir a saúde pública e a qualidade de vida da população.

Estabelecida a premissa de que há risco inerente ao contexto investigado, o modelo proposto considera que, no mínimo, três dimensões podem interferir no risco. A dimensão de "serviço" está relacionada ao modo de operação do posto, cujas variáveis de controle caracterizam condicionantes internas, como volume armazenado, número ou idade dos tanques. A dimensão "normativa" caracteriza a imposição aos requisitos estabelecidos pela norma de funcionamento e licenciamento, que classifica cada posto em função de processos de proteção e controle, bem como em relação à tipificação do entorno, estabelecendo condicionantes tanto internas quanto externas. A dimensão "ambiente" analisa algumas externalidades, como a existência de corpos hídricos e a geomorfologia do local.

O modelo aqui proposto considera uma composição linear das dimensões investigadas a fim de possibilitar a determinação de uma "Nota de Risco de Postos de Combustíveis" (NRPC), uma vez que, numa primeira análise, a ponderação de uma dimensão sobre a outra poderia aumentar o caráter subjetivo da análise. Segundo Sanchéz
(2008), a atribuição de um grau maior ou menor de importância a um impacto, ou, por analogia, a uma dimensão de análise que impacta o meio investigado, como o caso deste artigo, não é apenas uma tarefa técnica, mas também um exercício de juízo de valor que enseja subjetividade. Em matrizes de impacto, como o caso clássico da Matriz de Leopold (LEOPOLD et al., 1971), as avaliações interativas entre fatores e ações são correlacionadas às escalas de pontuação de importância e da magnitude. Entretanto, se por um lado a valoração da magnitude da alteração provocada pela ação é uma atribuição mais objetiva ou empírica na Matriz de Leopold, por outro, a estimativa da importância pode ser uma tarefa extremamente subjetiva. Ainda, se na análise é possível estabelecer que há importância diferenciada entre variáveis (ou dimensões), mas não sobre os seus graus de importância, a atribuição dos pesos pode ser aferida por análise hierárquica de processo (AHP), pelo julgamento de importância de cada propriedade na composição do perigo, conforme propôs Saaty (2008).

Assim, neste artigo, optou-se por atribuir o mesmo peso para as dimensões investigadas, de modo a minimizar a subjetividade e possibilitar a comparação, a posteriori, das notas obtidas para cada dimensão e, com isso, avaliar o grau de importância entre elas. Além disso, optou-se por empregar variáveis de controle do modelo que fossem de fácil inferência e interpretação, a partir de instruções normativas existentes, de características operacionais dos postos e oriundas de aspectos físicos do meio ambiente local.

A NRPC é obtida pela média aritmética das Notas de Risco das Dimensões (NR_DIM) consideradas, as quais são calculadas a partir de variáveis de controle aferidas em campo ou oriundas de bases de dados preexistentes (Equação 1).

$\mathrm{NRPC}=\sum_{\mathrm{i}=1}^{3} \frac{\text { NR_DIM }}{3}$

A NRPC varia de 1 a 3 pontos, em que 1 ponto é o grau mais baixo de risco e 3 pontos, o grau mais alto. A escala de valoração de NRPC para a designação do grau de risco das análises possui cinco níveis, conforme a Tabela 1 .

Tabela 1 - Escala de valoração de Nota de Risco de Postos de Combustíveis para designação do grau de risco.

\begin{tabular}{l|c} 
NRPC & Designação do grau de risco \\
\hline $1,0 \leq N R P C<1,4$ & Baixo \\
\hline $1,4 \leq N R P C<1,8$ & Leve \\
\hline $1,8 \leq N R P C<2,2$ & Médio \\
\hline $2,2 \leq N R P C<2,6$ & Alto \\
\hline $2,6 \leq N R P C<3,0$ & Grave
\end{tabular}

NRPC: Nota de Risco de Postos de Combustíveis

Fonte: adaptado de Fragoso (2014). 


\section{Nota de Risco Dimensão 1: Serviços}

Na Dimensão 1 - Serviços, consideram-se aspectos operacionais inerentes aos serviços prestados pelos postos de combustíveis. Para tanto, o modelo prevê a Nota de Risco da Dimensão 1 (NR_DIM1), calculada por meio da média aritmética das notas de risco atribuídas aos aspectos operacionais do posto revendedor (NR_Xi). A obtenção de NR_DIM1 é realizada de acordo com a Equação 2, que prevê quatro variáveis de controle (X1, X2, X3 e X4).

NR_DIM $1=\sum_{\mathrm{i}=1}^{4} \frac{\mathrm{NR} \_\mathrm{X}_{\mathrm{i}}}{4}$

Para valoração da variável X1, considerou-se o número de tanques subterrâneos utilizados para armazenagem de combustíveis. O legislador municipal estabeleceu na Lei Ordinária de Belém no 8.625 (BELÉM, 2008), de 7 de janeiro de 2008, no artigo $1^{\circ}$, inciso IV, o limite de $90.000 \mathrm{~L}$ como capacidade máxima de armazenamento para os postos revendedores estabelecidos em Belém. Para efeito de utilização desse dado como parâmetro de análise, partiu-se da constatação de que, por determinação legal, os postos revendedores somente poderão utilizar de 1 a 3 tanques subterrâneos para armazenamento, com capacidade nominal mínima de 30 mil L cada. Fragoso (2014) reporta que há postos funcionando na cidade de Belém em condições inferiores a esses limites, porém, relata a existência de outros que, por terem sua construção autorizada antes da entrada em vigor da lei municipal ora vigente, não foram alcançados por suas limitações e que, por essa razão, possuem mais de 3 tanques em operação, armazenando volumes superiores a $90.000 \mathrm{~L}$.

Por sua vez, a valoração da variável X2 foi realizada com base na capacidade de armazenamento de gasolina e diesel em termos de volume desses combustíveis, em consonância com a limitação imposta pela Lei Municipal nº 8.625 (BELÉM, 2008).

Para a variável X3, o aspecto operacional considerado foi a idade dos tanques, tomando como base a Instrução Normativa $n^{\circ}$ 001/2011, da Secretaria Municipal de Meio Ambiente de Belém (SEMMA, 2011), que estabelece no parágrafo único do art. $7^{\circ}$ a vida útil dessa espécie de equipamento como 20 anos.

Por fim, para a valoração da variável X4 foi considerada a ocorrência de trânsito de veículos sobre a área onde se encontram instalados os tanques subterrâneos, e que possam causar danos às tampas ou induzir recalques do solo por compactação ou adensamento.

A Tabela 2 apresenta a síntese dos condicionantes operacionais considerados na determinação de NR_DIM1.

\section{Nota de Risco Dimensão 2: Normativa}

A Nota de Risco da Dimensão 2 (NR_DIM2) é calculada por meio do valor atribuído à Nota de Risco da variável YABNT, considerando a classificação oferecida pela NBR n 13.786 , isto é, NR_DIM2=NR_YABNT.

Segundo a referida Norma ABNT, a classe do posto é definida por dois aspectos:

a. análise do ambiente do entorno, numa distância de $100 \mathrm{~m}$ a partir do seu perímetro;

b. existência de equipamentos ou sistemas que evitem a contaminação do subsolo devido a vazamentos, derramamentos e transbordamentos dos produtos comercializados.

No caso do ambiente do entorno do posto, são considerados os critérios descritos no Quadro 1 para a classificação em quatro níveis, numerados de 0 a 3 .

Além disso, a norma estabelece os respectivos equipamentos de uso obrigatório no desenvolvimento da atividade do posto, os quais compõem os processos de proteção e controle a serem adotados pelo empreendedor a fim de evitar vazamentos, derrames, transbordamentos ou corrosão dos equipamentos subterrâneos. Quanto maior a classe, maior o requerimento de nível de controle a fim de salvaguardar a área de influência do entorno (Quadro 2) e, portanto, maior o risco atribuído no evento de falha do sistema.

Dessa maneira, o modelo proposto considera a valoração da nota de risco da variável YABNT conforme apresentada na Tabela 3.

Tabela 2 - Síntese dos condicionantes operacionais empregados na determinação de Nota de Risco da Dimensão 1.

\begin{tabular}{|c|c|c|c|c|}
\hline $\begin{array}{l}\text { Variável } \\
\text { de } \\
\text { controle }\end{array}$ & $\begin{array}{l}\text { Aspecto } \\
\text { considerado }\end{array}$ & $\begin{array}{l}\text { Indicador de } \\
\text { controle }\end{array}$ & $\begin{array}{l}\text { Valor de } \\
\text { referência }\end{array}$ & $\begin{array}{l}\text { Nota de } \\
\text { Risco } \\
\text { Atribuída } \\
(\text { NR_X) }\end{array}$ \\
\hline \multirow{3}{*}{$X_{1}$} & \multirow{3}{*}{$\begin{array}{l}\text { capacidade de } \\
\text { armazenamento }\end{array}$} & \multirow{3}{*}{$\begin{array}{l}\text { quantidade } \\
\text { de tanques }\end{array}$} & 1 tanque & 1 \\
\hline & & & 2 tanques & 2 \\
\hline & & & $>3$ tanques & 3 \\
\hline \multirow{3}{*}{$x_{2}$} & \multirow{3}{*}{$\begin{array}{l}\text { capacidade de } \\
\text { armazenamento }\end{array}$} & \multirow{3}{*}{$\begin{array}{c}\text { volume } \\
\text { armazenado }\end{array}$} & até 30.000 L & 1 \\
\hline & & & até 60.000 L & 2 \\
\hline & & & $>60.000 \mathrm{~L}$ & 3 \\
\hline \multirow{3}{*}{$X_{3}$} & \multirow{3}{*}{$\begin{array}{c}\text { conservação dos } \\
\text { tanques }\end{array}$} & \multirow{3}{*}{$\begin{array}{l}\text { idade dos } \\
\text { tanques }\end{array}$} & até 5 anos & 1 \\
\hline & & & até 10 anos & 2 \\
\hline & & & $>10$ anos & 3 \\
\hline \multirow{3}{*}{$X_{4}$} & \multirow{3}{*}{$\begin{array}{c}\text { área de } \\
\text { rodagem e } \\
\text { estacionamento }\end{array}$} & \multirow{3}{*}{$\begin{array}{l}\text { trânsito de } \\
\text { veículos } \\
\text { sobre } \\
\text { tanques }\end{array}$} & inexistente & 1 \\
\hline & & & $\begin{array}{c}\text { somente } \\
\text { veículos de } \\
\text { pequeno porte }\end{array}$ & 2 \\
\hline & & & $\begin{array}{l}\text { qualquer tipo } \\
\text { de veículo }\end{array}$ & 3 \\
\hline
\end{tabular}

Fonte: adaptado de Fragoso (2014) 


\section{Nota de Risco Dimensão 3: Ambiente}

Na Dimensão 3 - Ambiente, consideram-se alguns aspectos ambientais que mantêm relação com as atividades realizadas nos postos de combustíveis. Para tanto, o modelo prevê a Nota de Risco da Dimensão 3 (NR_DIM3), calculada por meio da média aritmética das notas de risco atribuídas aos aspectos ambientais do posto revendedor (NR_Z (Equação 3), que prevê três variáveis de controle (Z1, Z2 e Z3), para as quais são determinadas as respectivas notas de risco.

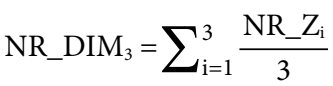

A escolha das variáveis de controle de NR_DIM 3 foi baseada em dois aspectos:

a. critérios urbanos e naturais que não foram atendidos pela NBR no 13.786 (Quadro 1);

b. disponibilidade de dados e informações para o modelo. Critérios como tipologia das atividades localizadas na área de influência dos postos (e.g. creches, asilos, escolas, etc.) ou captação de água subterrânea já estão contabilizados na NR_DIM2.

Demais aspectos que poderiam contribuir com a dimensão investigada, como direção do fluxo subterrâneo, permeabilidade do solo ou

Quadro 1 - Classificação do posto de serviço conforme o ambiente do entorno (NBR n 13.786).

\begin{tabular}{|c|c|}
\hline Classe & Característica do ambiente do entorno \\
\hline 1 & $\begin{array}{c}\text { Quando não possuir nenhum dos fatores } \\
\text { de agravamento das classes seguintes. }\end{array}$ \\
\hline Rede de drenagem de águas pluviais; rede \\
subterrânea de serviços (água, esgoto, \\
telefone, energia elétrica etc.); fossa em áreas \\
urbanas; edifício multifamiliar até quatro andares.
\end{tabular}

Quadro2-Distribuição dos processos de proteçãoe controlenecessários conforme a classificação do posto de serviço (NBR no 13.786).

\begin{tabular}{|c|c|}
\hline Classe & Processos de proteção e controle necessários \\
\hline \multirow{9}{*}{$0,1,2$} & $\begin{array}{l}\text { Detecção de vazamento, conforme a } \\
\text { ABNT NBR no } 13784 \text { (ABNT, 1997); monitoramento } \\
\text { em câmara de contenção sob a unidade abastecedora e } \\
\text { câmara de contenção para a unidade de filtragem. }\end{array}$ \\
\hline & Uma única válvula de retenção instalada em linha de sucção. \\
\hline & Câmara de acesso à boca-de-visita do tanque. \\
\hline & $\begin{array}{l}\text { Dispositivo para descarga selada; } \\
\text { câmara de contenção da descarga de combustível; } \\
\text { câmara de contenção sob a unidade abastecedora; } \\
\text { câmara de contenção na unidade de filtragem. }\end{array}$ \\
\hline & $\begin{array}{l}\text { Caixa separadora de água e óleo } \\
\text { para os canaletes de contenção. }\end{array}$ \\
\hline & Canalete de contenção. \\
\hline & $\begin{array}{l}\text { Tanque de parede simples: fabricado conforme ABNT NBR } \\
16116 \text { (ABNT, 2015), ou qualquer das opções da classe } 3 .\end{array}$ \\
\hline & $\begin{array}{c}\text { Tubulação: para trecho subterrâneo (não metálica } \\
\text { conforme ABNT NBR } 14722 \text { (ABNT, 2O11), de parede } \\
\text { simples para sistemas de sucção e de parede dupla } \\
\text { para sistemas de pressão); para trecho aéreo } \\
\text { (aço-carbono conforme ABNT NBR } 5590 \text { - ABNT, 2012). }\end{array}$ \\
\hline & $\begin{array}{l}\text { Válvula antitransbordamento ou válvula de retenção de } \\
\text { esfera flutuante' }{ }^{12} \text {, ou alarme de transbordamento². }\end{array}$ \\
\hline \multirow{4}{*}{3} & $\begin{array}{l}\text { Todos os processos de proteção e } \\
\text { controle da classe 2, exceto tanques. }\end{array}$ \\
\hline & $\begin{array}{l}\text { Válvula antitransbordamento ou } \\
\text { válvula de retenção de esfera flutuante }{ }^{12} \text {. }\end{array}$ \\
\hline & Monitoramento intersticial em tanques de parede dupla. \\
\hline & $\begin{array}{l}\text { Tanque de parede dupla: fabricado } \\
\text { conforme ABNT NBR } 16116 \text { (ABNT, 2015). }\end{array}$ \\
\hline
\end{tabular}

'A válvula de esfera flutuante não deve ser aplicada na(s) seguinte(s) condição(ões): (a) quando o sistema de abastecimento for por sucção e com a unidade abastecedora equipada com eliminador do ar, exceto se essa unidade for equipada com dispositivo e/ou mecanismo que elimine a possibilidade de derrames através do eliminador de ar; ou (b) quando o sistema de abastecimento for por sucção em unidades abastecedoras de álcool, devido à possibilidade de transbordo pelo densímetro; ou (c) quando o tanque receber retorno da unidade de filtragem. ${ }^{2}$ Quando aplicada válvula de esfera flutuante ou alarme de transbordamento no tanque cujo ponto de descarga de combustível, direto ou a distância, estiver localizado fora da área de abastecimento, ou seja, não protegido pelo canalete da área de abastecimento, esse ponto de descarga de combustivel deve possuir piso em concreto armado e canalete próprio, distante no máximo 0,50 m da borda da câmara de descarga de combustível e deve direcionar o fluxo para uma caixa separadora de água e óleo.

Tabela 3 - Síntese dos condicionantes normativos empregados na determinação da Nota de Risco Dimensão $2\left(\mathrm{NR}_{-} \mathrm{Y}_{\mathrm{ABNT}}\right)$.

\begin{tabular}{l|c|c}
\multirow{3}{*}{ Variável } & $\begin{array}{c}\text { Classe } \\
\text { NBR no } 13.786\end{array}$ & Nota de Risco NR_Y $\mathbf{A}_{\text {ANBT }}$ \\
\cline { 2 - 3 } & 0 & 1 \\
\cline { 2 - 3 } Y $_{\text {ANBT }}$ & 1 & 1 \\
\cline { 2 - 3 } & 2 & 2 \\
\hline
\end{tabular}

Fonte: adaptado de Fragoso (2014) 
topografia, simplesmente não existiam no período investigado e, portanto, não foram incluídos nesta avaliação.

Assim, para a variável de controle Z1 considerou-se a proximidade das instalações em relação aos corpos hídricos superficiais relevantes, tais como galerias e canais a céu aberto, córregos, rios e igarapés. Ocorrendo lançamento de combustíveis nesses corpos hídricos, seria bastante considerável a possibilidade da rápida dispersão de contaminantes, aumentando a área atingida pelos efeitos do acidente, seja pela mobilidade intrínseca do composto, seja pelo efeito das marés da região sobre os canais de drenagem, pelo significativo volume de águas pluviais da região ou pelos longos trechos percorridos por canais de drenagem a céu aberto no ambiente urbano de Belém. Fragoso (2014) reporta a existência de posto de combustível a poucos metros de um importante canal de drenagem de Belém, que recebe grande volume de drenagem e está sujeito à variação das marés, sendo constante seu transbordamento. Nesse cenário, a variável $\mathrm{Z} 1$ assume valores superiores quanto mais próximos os postos estiverem dos corpos hídricos.

Por sua vez, para a valoração da variável Z2 foi considerada a distância entre postos de combustíveis. Nesse caso, destacam-se da Lei Ordinária de Belém/PA no 8.500/2006, após modificação efetuada pela Lei Ordinária de Belém nº 8.625/2008, as seguintes disposições, claramente voltadas à proteção do meio ambiente: "Art. $2^{\circ}$ : a construção dos postos revendedores de combustíveis automotivos (PRCAs) deverá satisfazer às exigências normativas da ABNT/NBR [Associação Brasileira de Normas Técnicas] e da Resolução nº 273/00, do CONAMA e as seguintes: I - o local pretendido para a construção dos PRCAs deverá resguardar 500 (quinhentos) metros de distância para outros estabelecimentos semelhantes" (BELÉM, 2008). Entretanto, Fragoso (2014) reporta o desrespeito a tais limitações por parte de alguns postos de combustíveis de Belém. Portanto, para a variável Z2, o modelo considera que, quanto menor a distância verificada entre as instalações de postos revendedores de combustíveis, maior poderá ser o volume de contaminante liberado no solo para uma mesma região, se houver vazamentos concomitantes e, portanto, maiores as notas de risco atribuídas.

A variável Z3 considera aspectos da formação dos solos de Belém, porém com abordagem superficial. Nesse caso, somente foi considerada a existência de áreas de várzea e terra firme, notoriamente mapeadas na cidade de Belém, e que podem caracterizar locais com solos saturados (encharcados), com lençol freático raso ou aflorante (várzea) e regiões de topografia mais elevada, com solo seco (terra firme). Assim, regiões com maior suscetibilidade a saturações do solo (encharcamentos) apresentam potencial de risco maior, no evento de derrame de combustível, pela maior mobilidade do contaminante, tanto em superfície quanto em sub-superfície. A Tabela 4 apresenta a valoração considerada na determinação de NR_DIM3.

\section{RESULTADOS E DISCUSSÃO}

\section{Notas de Risco por Dimensões}

Os resultados obtidos pela aplicação do método proposto estão ilustrados na Figura 2, onde é possível inferir que as notas de risco calculadas para as dimensões 1 e 3 (NR_DIM1 e NR_DIM3), que tratam de aspectos de serviços e do ambiente, respectivamente, apresentaram variações de magnitude entre 1,75 e 3,00 (NR_DIM1) e entre 1,33 e 2,67 (NR_DIM3). Essas faixas de valores se inserem na designação do grau de risco que vai de leve a grave, conforme valoração definida na Tabela 1. Além disso, para essas dimensões, a variação das notas por posto é razoavelmente equilibrada para a faixa de valores observada, com predominância de valores de maior risco para NR_DIM1 e valores de menor risco para NR_DIM3.

Por outro lado, a análise da Figura 2 possibilita verificar que as NR_DIM2 apresentam menor faixa de variação de valores entre postos, situando-se entre 2 e 3 , com predominância na valoração 3 , mais restritiva, o que confere a designação do grau de risco que vai de médio a grave, conforme valoração definida na Tabela 1 .

A Figura 3 ilustra como ocorreu a distribuição das notas de risco 3, 2 e 1 por variável de controle estudada e por dimensão. Com relação à Dimensão 1 - Serviços, a referida figura ilustra que os aspectos operacionais dos postos receberam majoritariamente a nota 3 (valor grave de risco) em todas as 4 variáveis investigadas. A maior parte dos postos possui mais de 3 tanques (66\% de notas de risco 3 atribuídas à variável $\mathrm{X} 1$ ); armazenamento superior a $60 \mathrm{mil} \mathrm{L}$ (67\% de notas de risco 3 atribuídas à variável X2); e permissão de tráfego sobre a área de armazenamento ( $88 \%$ de notas de risco 3 atribuídas à variável X4). Por outro lado, em função da exigência legal da troca de tanques por nova tecnologia, a idade desses está mais bem distribuída nos postos investigados, com somente $40 \%$ com idade superior a 10 anos e, portanto, nota de risco

Tabela 4 - Síntese das condicionantes ambientais empregadas na determinação de Nota de Risco Dimensão 3.

\begin{tabular}{|c|c|c|c|c|}
\hline $\begin{array}{l}\text { Variável } \\
\text { de } \\
\text { controle }\end{array}$ & $\begin{array}{l}\text { Aspecto } \\
\text { considerado }\end{array}$ & $\begin{array}{l}\text { Indicador de } \\
\text { controle }\end{array}$ & $\begin{array}{l}\text { Valor de } \\
\text { referência }\end{array}$ & $\begin{array}{l}\text { Nota de } \\
\text { Risco } \\
\text { Atribuida }\end{array}$ \\
\hline \multirow{3}{*}{ Z1 } & \multirow{3}{*}{$\begin{array}{c}\text { proximidade } \\
\text { de corpos } \\
\text { hídricos }\end{array}$} & \multirow{3}{*}{$\begin{array}{l}\text { distância } \\
\text { em metros }\end{array}$} & $>100$ & 1 \\
\hline & & & 20 a 100 & 2 \\
\hline & & & $<20$ & 3 \\
\hline \multirow{3}{*}{ Z2 } & \multirow{3}{*}{$\begin{array}{l}\text { proximidade } \\
\text { entre postos }\end{array}$} & \multirow{3}{*}{$\begin{array}{l}\text { afastamento } \\
\text { em metros }\end{array}$} & $>100$ & 1 \\
\hline & & & 50 a 100 & 2 \\
\hline & & & $<50$ & 3 \\
\hline \multirow[t]{2}{*}{ Z3 } & \multirow{2}{*}{$\begin{array}{c}\text { geomorfologia } \\
\text { do solo } \\
\text { amazônico }\end{array}$} & \multirow{2}{*}{$\begin{array}{l}\text { aspecto do solo } \\
\text { (encharcamento) }\end{array}$} & $\begin{array}{l}\text { terra } \\
\text { firme }\end{array}$ & 2 \\
\hline & & & várzea & 3 \\
\hline
\end{tabular}

Fonte: adaptado de Fragoso (2014) 
3 (variável X3). Assim, a média de distribuição das notas de risco 3, 2 e 1 para a Dimensão 1 - Serviços foi de 65, 28 e 7\%, respectivamente.

Por sua vez, a Dimensão 2 - Normativa apresentou resultados bastante favoráveis ao risco, uma vez que $90 \%$ dos postos receberam nota de risco 3 (risco grave), a partir da classificação atribuída pela
NBR n ${ }^{\circ}$ 13.786, conforme se observa na Figura 3. Essa evidência está associada aos aspectos bastante restritivos da NBR $\mathrm{n}^{\circ} 13.786$, os quais influenciam na valoração atribuída a cada posto.

Os aspectos ambientais da Dimensão 3 - Ambiente conferiram resultados menos favoráveis ao risco. Somente $24 \%$ dos postos estavam

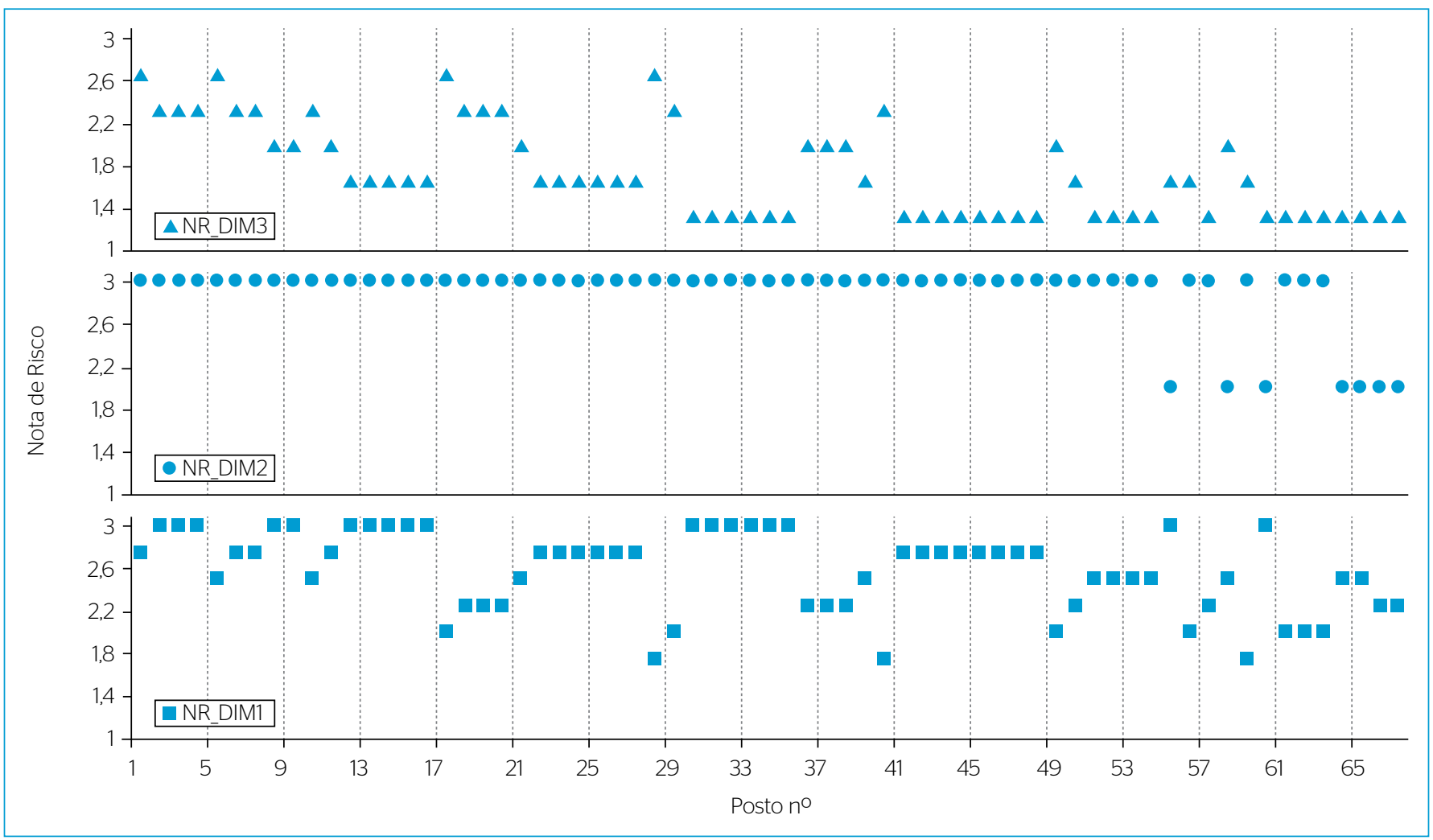

Figura 2 - Notas de Risco de cada posto, por dimensão investigada.



Figura 3 - Distribuição percentual da Nota de Risco nas dimensões e variáveis investigadas. 
próximos a corpos hídricos e receberam nota de risco 3 (variável Z1). Quase não há postos que mantêm distâncias entre si menores do que o estabelecido por norma. Apenas 6\% receberam nota de risco 3 (variável Z2). Quanto à localização em relação à geomorfologia da região, $54 \%$ dos postos receberam nota de risco 3 por estarem localizados em região de várzea, com topografia mais baixa e passível de alagamento. Assim, a média de notas de risco foi de $26 \%$, inferior, portanto aos valores médios das demais dimensões. As distribuições percentuais médias das notas de risco por dimensões estão sintetizadas na Tabela 5 .

Os valores médios de $\mathrm{NR}=3$ (risco grave) e $\mathrm{NR}=1$ (risco leve) foram traçados no gráfico da Figura 4, empregando a mesma escala nos dois eixos, de modo a possibilitar a identificação de duas regiões no gráfico que indicam risco grave (região I) e risco leve (região II).

Como o modelo emprega uma ponderação linear, ou seja, atribui o mesmo peso de importância para cada dimensão, a Figura 4 permite inferir a influência de cada dimensão sobre a nota de risco final, a partir da valoração dos dados de campo. Ou seja, nos casos investigados,

Tabela 5 - Distribuição média das Notas de Risco por dimensão investigada.

\begin{tabular}{c|c|c|c} 
NR & DIM1 (\%) & DIM2 (\%) & DIM 3 (\%) \\
\hline 3 & 65 & 90 & 26 \\
\hline 2 & 28 & 10 & 23 \\
\hline 1 & 7 & 0 & 51 \\
\hline TOTAL & 100 & 100 & 100 \\
\hline
\end{tabular}

NR: Nota de Risco; DIM: dimensão.

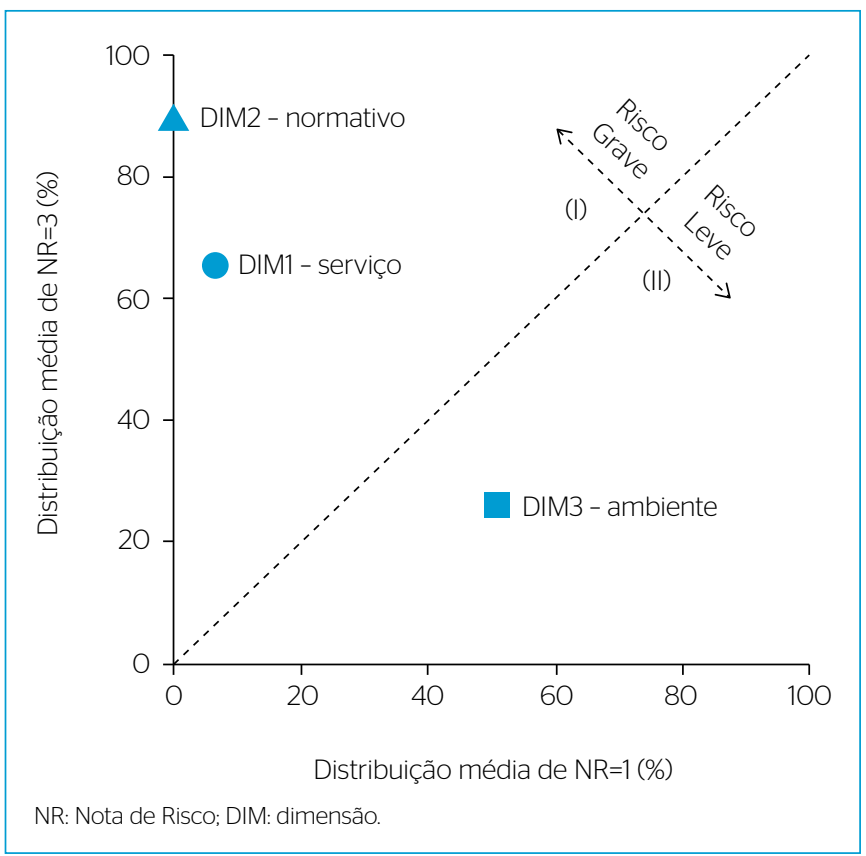

Figura 4 - Proporção de influência das Notas de Risco por dimensão na Nota de Risco de Postos de Combustíveis. em média, a proporção de influência na NRPC foi maior nos critérios normativos e operacionais dos postos do que nas variáveis ambientais de controle escolhidas.

\section{Avaliação da Nota de Risco de Postos de Combustíveis e da Nota de Risco de Postos de Combustíveis por bairro}

Após determinação e análise das notas de risco para cada dimensão (NR_DIM), calculou-se o valor de NRPC (Equação 1) para cada um dos 67 postos investigados. Os valores obtidos variaram entre 1,86 e 2,81 . Essas notas designam o grau de risco variando de médio a grave, demonstrando que nenhum posto na RMB apresenta relação com o meio urbano ao seu redor que seja considerada de risco leve ou baixo, conforme a metodologia proposta.

Dos valores de NRPC calculados (Figura 5), 14,9; 68,9 e 16,5\% dos postos apresentaram risco grave, alto e médio, respectivamente. Há bairros com postos de combustíveis com variações de risco desde médio até grave, o que impossibilita a simples estimativa de um valor de risco médio por bairros, pois não é possível diminuir o risco grave de um posto em função da existência de postos com menores riscos no mesmo bairro, ainda que se atribua ponderação aos riscos. Assim, neste artigo, a extrapolação do valor de NRPC para um valor de NRPCbairro, que representa o risco global do bairro em questão, foi realizada considerando o maior valor de NRPC de cada bairro, de modo que, na análise, os riscos maiores se sobrepõem aos riscos menores. A Figura 6 ilustra o resultado da extrapolação de NRPC para NRPCbairro, a fim de possibilitar

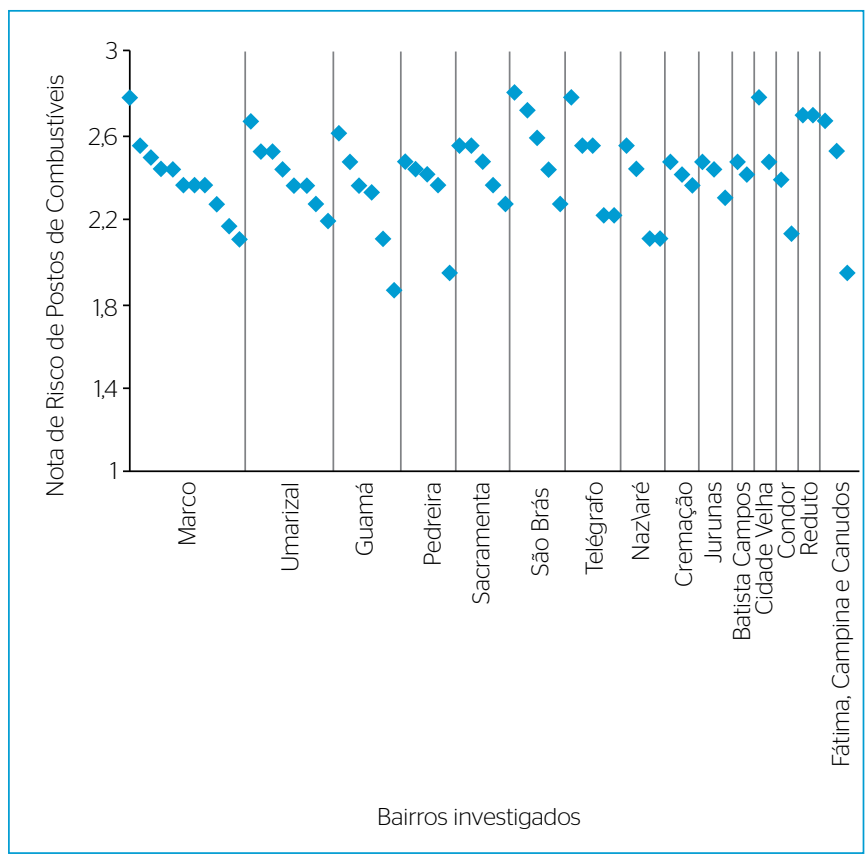

Figura 5 - Valores de Nota de Risco de Postos de Combustíveis calculados e distribuídos por bairros investigados. 
o estudo da espacialidade do risco na PLP de Belém, representada por meio do mapa de risco da Figura 7.

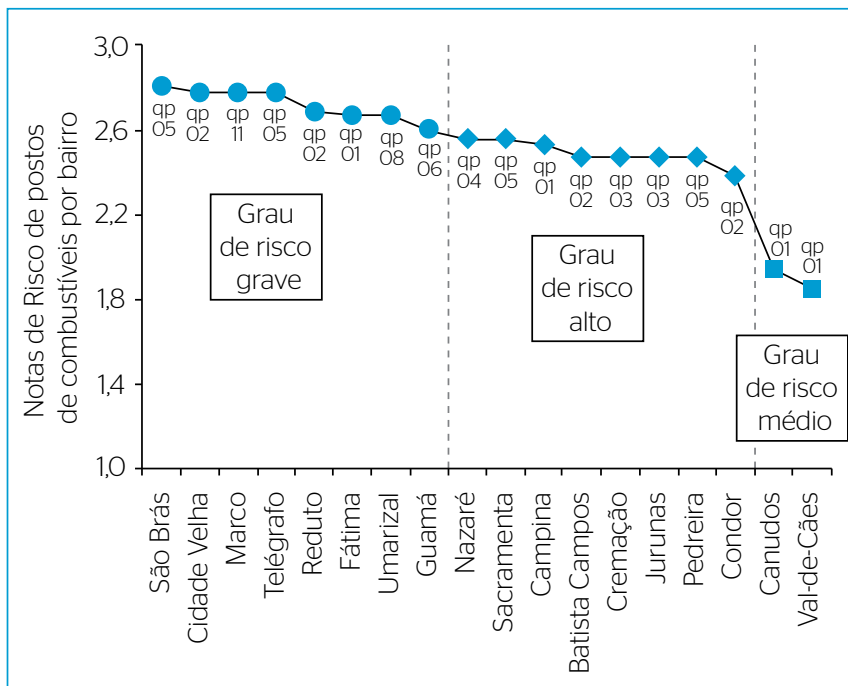

Bairros da Primeira Légua Patrimonial da RMB

Figura 6 - Nota de Risco de Postos de Combustíveis por bairros da Primeira Légua Patrimonial de Belém.



Figura 7 - Espacialidade de Nota de Risco de Postos de Combustíveis por bairros na Primeira Légua Patrimonial de Belém.

\section{CONCLUSÕES}

O modelo proposto é simples, porém se constitui como uma boa e rápida ferramenta para auxílio na gestão ambiental e urbana de municípios, uma vez que emprega variáveis de controle de fácil obtenção, por exemplo, junto aos órgãos de licenciamento, em cadastros públicos ou em cartografias da região investigada. Esse é o caso de muitos municípios do Pará, inclusive da própria RMB. Nessas localidades, aspectos quantitativos importantes, como informações sobre hidrogeologia da região, direção de fluxo da água subterrânea, profundidade do lençol freático e permeabilidade do solo, simplesmente não estão disponíveis, requerendo investimentos financeiros e técnicos, além de tempo, para a sua obtenção, sendo, por isso, substituídos pelas variáveis de controle já descritas.

A aplicação do modelo no estudo do caso dos postos de combustíveis na PLP de Belém foi exitosa na identificação e na hierarquização do potencial de risco associado à existência desses no âmbito urbano, em função das três dimensões consideradas. Os resultados da modelagem por postos demonstraram que a maioria possui risco alto, apesar de empreender práticas de controle. Notou-se, igualmente, que há poucos postos com risco médio, refletindo uma ponderação grande sobre aspectos normativos exigidos para a licença e a operação desses empreendimentos, os quais, em todos os casos analisados, receberam valorações mais restritivas. As notas de risco normativas, portanto, foram as que mais influenciaram nos resultados rigorosos calculados, o que leva a crer que há necessidade de melhor adaptação dos postos investigados às exigências normativas.

Por outro lado, o método de extrapolação empregado para obtenção da nota de risco de postos por bairros foi conservador, na medida em que sobrepôs um risco maior sobre todos os outros menores. Assim, os resultados da distribuição espacial da nota de risco por bairro demonstraram que há muitos bairros com risco grave e alto. Entretanto, os bairros que possuem risco grave são aqueles cujo processo de expansão urbana é mais recente e intenso e que possuem maior quantidade de postos. Por sua vez, os bairros mais centrais e antigos da PLP possuem risco alto, indicando que os postos já existentes têm melhor adequação normativa em relação àqueles onde a expansão urbana é mais recente.

Estudos voltados à produção de mapas de risco, considerando diversas fontes de poluição, não são corriqueiros na RMB, especialmente no que diz respeito à existência de postos de combustíveis. Assim, análises comparativas diretas não puderam ser realizadas. Entretanto, estudos como os relatados por Lisboa et al. (2016), que envolveram a determinação da vulnerabilidade dos aquíferos de Belém, em associação com a caracterização do perigo de um dado poluente, a fim de gerar o consequente risco, já estão em curso, de maneira cooperativa entre os grupos de pesquisa, de modo a implementá-los no contexto abordado neste artigo. 


\section{REFERÊNCIAS}

AGÊNCIA NACIONAL DO PETRÓLEO, GÁS E BIOCOMBUSTIVEL (ANP) (2014) ANP. Consulta Posto Web. Disponível em: <http:/l www.anp.gov.br/?id=1086>. Acesso em: 10 jun. 2014.

ALLER, L.; BENNET, T.; LEHR, H.J.; PETTY, J.R.; HACKETT, G. (1987) DRASTIC: A standardized system for evaluating groundwater pollution potential using hydrogeologic settings. US.EPA-600/2-87-035. Estados Unidos: USEPA. 622 p.

ASSOCIAÇÃO BRASILEIRA DE NORMAS TÉCNICAS (ABNT). (1997) NBR 13784. Detecção de vazamento em postos de serviço. Rio de Janeiro: ABNT.

(2011) NBR 14722: Armazenamento de líquidos inflamáveis e combustíveis - Tubulação não metálica subterrânea - Polietileno. Rio de Janeiro: ABNT.

(2012) NBR 5590:2015 - Tubos de aço-carbono com ou sem solda longitudinal, pretos ou galvanizados - Requisitos. Rio de Janeiro: ABNT.

(2015) NBR 16116. Armazenamento de líquidos inflamáveis e combustíveis - Tanque metálico subterrâneo - Especificação de fabricação e modulação. Rio de Janeiro: ABNT.

BELÉM. (2006) Lei no 8.500, de 7 de janeiro de 2008. Dispõe sobre a construção e funcionamento de postos revendedores de combustíveis automotivos PRCA no Município de Belém, e dá outras providências. Diário Oficial do Município, Belém, p. 6.

(2008) Lei no 8.625, de 7 de janeiro de 2008. Altera dispositivos da Lei no 8.500, de 13 de janeiro de 2006, que dispõe sobre a construção e funcionamento de postos revendedores dos combustíveis automotores - PRCA, no município de Belém, e dá outras providências. Diário Oficial do Município, Belém, p. 3.

BRASIL. (1986) Resolução CONAMA $n^{\circ} 20$, de 18 de junho de 1986. Classificação de águas, doces, salobras e salinas do Território Nacional. Diário Oficial da União, Brasília.

CHIARAMONTE, E.A.S.; KAUTZMANN, R.M.; SAMPAIO, C.H.; ZABADAL, J.R.S.; ALIFANTES, J.; GARCIA, R.L. (2O12) Propagação de compostos da gasolina em solos: 1. Zona não saturada. Engenharia Sanitária e Ambiental, v. 17, n. 1, p. 33-40.

CORSEUIL, H.X.; MARINS, M.D.M. (1997) Contaminação de águas subterrâneas por derramamentos de gasolina: o problema é grave? Engenharia Sanitária e Ambiental, v. 2, n. 2, p. 50-54.

DEPARTAMENTO NACIONAL DE TRÂNSITO (DENATRAN). (2O16) Frota de veículos - 2016. Disponível em: <http://www.denatran.gov. br/index.php/estatistica/261-frota-2016>. Acesso em: 28 set. 2016.

FOSTER, S.S.D.; HIRATA, R.C.A. (1993) Determinação do risco de contaminação das águas subterrâneas: um método baseado em dados existentes. Boletim do Instituto Geológico, São Paulo, n. 10.
FRAGOSO, E.C. (2014) Análise multicriterial de risco de contaminação do solo por combustíveis automotivos no espaço da primeira légua patrimonial de Belém. 104f. Dissertação (Mestrado em Desenvolvimento e Meio Ambiente Urbano) - Universidade da Amazônia, Belém.

KONEČNÝ, F; BOHÁČEK, Z; MÜLLER, P.; KOVǍROVÁ, M.; SEDLAČKOVÁ, I. (2003) Contamination of soils and groundwater by petroleum hydrocarbons and volatile organic compounds - Case study: ELSLAV BRNO. Bulletin of Geosciences, v. 78, n. 3, p. 225-239.

LEOPOLD, L.B.; CLARKE, F.S.; HANSHAW, B.; BALSLEY, J.R. (1971) A procedure for evaluating environmental impact. Geological Survey Circular, n. 645.13 p.

LISBOA, E.G.; MENDES, R.L.R.; BELLO, L.A.L. (2016) Mapeamento do risco de contaminação das águas subterrâneas em zonas urbanas: proposta de um índice de perigo fuzzy-AHP. Revista da Universidade Vale do Rio Verde, Três Corações, v. 14, n. 2, p. 238-252.

MOSCHINI, L.E.; SANTOS, J.E.; PIRES, J.S.R. (2005) Environmental diagnosis of risk areas related to gas stations. Brazilian Archives of Biology and Technology, v. 48, n. 4, p. 657-666.

OLIVEIRA, W.; TAGLIARINI, E.M.; TANCREDI, A.C.F.N.S.; PACHECO, L.F.C. (2002) Contaminação por compostos de petróleo na área do residencial Olimpus - Belém - Pará. In: CONGRESSO BRASILEIRO DE AGUAS SUBTERRÂNEAS, 12. Anais... Suplemento. Disponível em: <https://aguassubterraneas.abas.org/asubterraneas/article/ view/22860/15007>. Acesso em: 07 nov. 2016.

SANCHÉZ, L.E. (2008) Avaliação de Impacto Ambiental: conceitos e métodos. São Paulo: Oficina de Textos. 495 p.

SAATY, T.L. (2008) Decision making with the analytical hierarchy process. International Journal of Services Sciences, v. 1, n. 1, p. 83-98.

SECRETARIA MUNICIPAL DE MEIO AMBIENTE (SEMMA) (2O11). Instrução Normativa no 001, de 01 de fevereiro de 2011. Disciplina o processo de licenciamento ambiental dos postos revendedores de derivados de petróleo e biocombustíveis, localizados no Município de Belém, bem como os procedimentos a serem adotados em caso de incidentes e/ou acidentes ambientais e constatação de passivos ambientais dos mesmos. Diário Oficial do Município, Belém, p. 6-8.

TERRÉS, I.M.M.; MIÑARRO, M.D.; FERRADAS, E.G.; CARACENA, A.B.; RICO, J.B. (2010). Assessing the impact of petrol stations on their immediate surroundings. Journal of Environmental Management, v. 91, n. 12. DOI: 10.1016/j.jenvman.2010.08.009

TIBURTIUS, E.R.L;; PERALTA-ZAMORA, P.G.; LEAL, E.S. (2004) Contaminação de águas por BTXs e processos utilizados na remediação de sítios contaminados. Química Nova, v. 27, p. 441-446.

TRINDADE JÚNIOR, S.C.C. (1998) A cidade dispersa: os novos espaços de assentamentos em Belém e a reestruturação metropolitana. 408f. Tese (Doutorado em Geografia Humana) Departamento de Geografia, Universidade de São Paulo, São Paulo. 